\title{
Australian Contemporary Msanagement of Synchronous Metastatic Colorectal Cancer
}

ABBREVIATED TITLE:

Management of synchronous metastatic colorectal carcinoma.

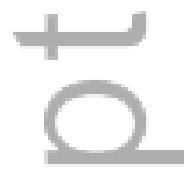

=

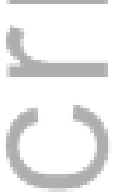

MESH headings:

Colorectal neoplasms

Secondary

Surgery

Antineoplastic combined chemotherapy protocols

Biological therapy

*University of New South Wales.

**Melbourne university

***Monash University

****Monash University and Alfred-Cabrini academic department of surgery.

\section{Contact details}

Dr Phillip Malouf

176 Queen St Woollahra, NSW 2025

p.malouf@unsw.edu.au

ph 0418114674

Word count:

ABSTRACT: 250

2 tables and 2 figures are presented within the paper.

This is the author manuscript accepted for publication and has undergone full peer review but has not been through the copyediting, typesetting, pagination and proofreading process, which may lead to differences between this version and the Version of Record. Please cite this article as doi: 10.1111/ans.13619

This article is protected by copyright. All rights reserved. 
TEXT: 2738 words including main text, tables and figures but excluding abstract, references and acknowledgements.

\section{Abstract}

\section{Introduction}

This article outlines current Australian multidisciplinary treatment of synchronous metastatic colorectal adenocarcinoma and assesses the factors that influence patient outcome.

\section{Methods}

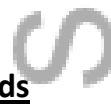

This is a retrospective analysis of the prospective "Treatment of Recurrent and Advanced Colorectal Cancer" registry, describing the patient treatment pathway and documenting extent of disease, resection of the colorectal primary and metastases, chemotherapy and biological therapy use. Cox regression models for progression-free (PFS) and overall survival (OS) were constructed with a comprehensive set of clinical variables. Analysis was intention to treat, quantifying the effect of treatment intent decided at the multidisciplinary team meeting (MDT).

\section{$\underline{\text { Results }}$}

1109 patients presented with synchronous metastatic disease between July 2009 and November 2015. Median follow-up 15.8 months. 4.4\% (group 1) had already had curative resections of primary and metastases prior to MDT, 22.2\% (group 2) were considered curative but were referred to MDT for opinion and/or medical oncology treatment prior to resection; $70.2 \%$ were considered palliative at MDT (group 3).

Overall, $83 \%$ received chemotherapy, $55 \%$ had their primary resected and $23 \%$ had their metastases resected; $13 \%$ of resections were synchronous, $20 \%$ were staged with primary resected first and $62 \%$ had only the colorectal primary managed surgically. 
Performance status, metastasis resection (R0 v R1 V R2 v no resection), resection of the colorectal primary and treatment intent determined at MDT were the most significant factors for progression-free and overall survival.

\section{Conclusions}

This is the largest Australian series of synchronous metastatic colorectal adenocarcinoma and offers insight into the nature and utility of contemporary practice.

\section{Australian Contemporary management of Synchronous}

\section{Metastatic Colorectal Cancer}

\section{INTRODUCTION}

Synchronous metastatic colorectal cancer represents $25 \%$ of colorectal carcinoma presentations and yet the management strategies are remarkably heterogeneous. The current paradigm suggests that we focus on the control of metastatic disease unless both primary tumour and all metastases can be resected(1-4) but only 20$30 \%$ have resectable metastases(5); the remaining $70-80 \%$ might be offered chemotherapy but $13.9-18 \%$ subsequently obstruct(6), $3 \%$ have a significant haemorrhage and $6.1 \%$ perforate(5) such that $23 \%$ of those with initially unresectable distant disease ultimately need their primary managed, irrespective of any downstaging. Those with a sufficient response to neoadjuvant chemotherapy might proceed to curative resection but the proportion can be as low as $4 \%(5)$.

The published literature focuses on younger patients with good performance status having aggressive treatments $(2,3,7-11)$, so there is limited documentation of the outcomes for the frailer, older patients often seen in routine practice and even less evidence to guide their treatment(12-14).

Treatment intent determines the management pathway. This treatment decision is made in the multidisciplinary setting (MDT). The effect of this decision on outcomes has never been explored. 
Noting the lack of randomised clinical trials evaluating the optimal sequence of treatment, our primary objective in this article is to prospectively document the treatment pathway and treatment outcomes of a large Australian cohort of patients presenting with synchronous metastatic disease; to assess the effects of clinical variables and contemporary multidisciplinary treatment on progression-free (PFS) and overall survival (OS).

Methods:

=

The Treatment of Recurrent and Advanced Colorectal Cancer (TRACC) registry is a prospective database of metastatic colorectal cancer with 14 contributing centres Australia-wide(15). Data have been collected since July 2009 and are entered at point of care.

The registry was validated prior to analysis by comparison to clinic records. All patients presenting with histologically-confirmed synchronous metastatic colorectal adenocarcinoma from July 2009 to November 2015 were included in the analysis. Appropriate ethical approval was obtained for this analysis.

Treatment intent was classified as curative or palliative; curative patients either had their primary tumour and distant disease resected prior to referral (group 1) or were referred for medical oncology input and/or treatment prior to a possible resection (group 2) while the remainder (group 3) were managed with palliative intent.

Demographic statistics and Cox regression analysis were performed with SAS 9.4 (SAS Institute Inc., Cary, NC, USA.). Results are presented as hazard ratios (HR). Final Cox models were created by stepwise backward elimination. Analysis was intention to treat.

The development and maintenance of the registry has been sponsored in part by Roche Pty Itd (Australia).

RESULTS

1109 patients had synchronous metastatic colorectal adenocarcinoma within a cohort of 1890 patients.

Demographics and disease characteristics are displayed in table 1. 


\section{Patterns of chemotherapy and biologic agent use}

928 patients (83.7\%) received chemotherapy: 55\% FOLFOX, 15\% single agent 5-Flourouracil and $12 \%$ XELOX. Reasons for ceasing first line chemotherapy and the proportion receiving a second-line agent are outlined in figure 1. Palliative patients commenced their first-line chemotherapy regimen within a median 36 days of diagnosis (range 0 days to 2.3 years).

579 (52.2\%) patients had Bevacizumab therapy, 8 had Cetuximab and 48 patients had SIRT sphere therapy to in the metastases.

\section{Patterns of surgical management}

612 patients had their primary tumour resected (55.2\%) and 253 patients had their metastases resected (22.8\%); $13.2 \%$ were synchronous, $19.7 \%$ were staged "primary first", 3.3\% were "liver first" and 382 patients only had the primary tumour resected (62.4\%). 391 (63.8\%) had their primary tumour resected before chemotherapy commenced, while 123 (20.1\%) had chemotherapy upfront.

The majority of patients $(814,73.4 \%)$ were considered palliative (i.e. group 3 ) at MDT. This palliative intent group still had $45.5 \%$ (370 of 814 ) of their colorectal primary tumours resected and $8.6 \%$ (70 of 814 patients) had their metastases resected. Reasons for primary resection in the palliative group were surgeon decision (45\%), obstruction (33\%) but $4 \%$ achieved curative resection of metastases. Figure S1.

160 liver resections were performed (14.4\%), 11 lung resections (1.0\%) and 83 resections of other disease (7.5\%), the majority being peritoneal deposits resected with the colorectal primary. Resection of metastases was $\mathrm{R} 0$ in $76.0 \%, \mathrm{R} 1$ in $6.6 \%$ and $\mathrm{R} 2$ in $17.4 \%$.

Rectal cancer management is explored in supporting document 1.

\section{Elderly patients}

This article is protected by copyright. All rights reserved. 
174 of the patients were 80 years or older. $11.5 \%$ were curative and $88.5 \%$ were palliative. 85 (48.9\%) had chemotherapy; the most common first-line regimen received was single agent capecitabine (19.5\%). Only 10 of 174 (5.7\%) had both primary and metastases resected. Mean duration of first-line chemotherapy was 68.3 days compared to 141 days for those under 80 years of age $(P<0.001)$ and the older group were less likely to use a second line agent $(13.8 \%$ v 53.0\% p<0.001). Median PFS and OS were lower in this older age group when compared to those less than 80 years of age (PFS 9.0 v 12.2 months $p<0.001$, OS $12.5 \vee 24.9$ months $P<0.001$ ).

\section{Progression free and overall survival}

Unadjusted Hazard ratios and Cox modelling for PFS and OS are shown in table 2. Five-year progression-free survival was $41 \%$ for group 1, $16 \%$ for group 2 and $2 \%$ for group 3 . Five-year overall survival was $84 \%$ for group $1,41 \%$ for group 2 and $5 \%$ for group 3.664 patients ( $59.9 \%$ of all patients) have subsequently progressed or recurred at a median follow-up of 15.8 months. Figure S2 contains relevant Kaplan Meier survival curves.

\section{Examining the effect of receiving curative treatment}

Surgery is the only chance for cure in metastatic colorectal carcinoma(11). Analysis of those having both primary and metastases resected showed that male sex (HR 1.5 p 0.02), poor performance status (HR $5.3 \mathrm{p}$ 0.009) and synchronous resection (HR 1.65 p 0.01) influenced progression-free survival while age (HR $1.02 \mathrm{p}$ 0.03 ) and treatment intent (HR 8.4 for palliative $p<0.0001)$ were the only variables that influenced overall survival.

Median PFS for synchronous resection was 13.4 months, metastases-first 26.5 months and primary-first 25.0 months $(p<0.0001)$. Median OS for those synchronously resected was 44.0 months, those having the metastases resected first was 40.8 months ( $p$ 0.001); median OS for those having the primary resected first could not be calculated as more than $50 \%$ were alive at analysis at 93 months.

Figure 2 outlines the pathway for the subset of resected patients having curative resections (R0/R1)

\section{DISCUSSION:}

This article is protected by copyright. All rights reserved. 
This paper outlines real-life, contemporary patient management and to our knowledge, represents the largest Australian cohort of patients with synchronous metastatic colorectal carcinoma.

Performance status is the most significant determinant of PFS and OS. The inclusion of elderly and poor performance status patients in this analysis is critical to a comprehensive overview; their reduced use of chemotherapy and reduced tolerance of first-line chemotherapy regimens is in keeping with the literature(12, 16).

$=$

Curative intent had a marked effect on survival compared to palliation. Indeed, it remained influential even when modelled with variables used to determine the feasibility of curative treatment. Curative intent significantly improved both PFS and OS when compared to a palliative approach even though almost half of the palliative group had their primary tumour resected and most patients received some form of chemotherapy, reinforcing the importance of considering aggressive surgical and medical therapy for all fit patients. Although most patients were considered palliative, $4 \%$ of the palliative group achieved curative resection demonstrating that a small proportion do have a better than expected response to treatment.

The majority of the cohort had their primary tumour resected and the primary was usually resected before the metastases. Resection of the colorectal primary still improved PFS (HR $0.58 \mathrm{p}<0.0001)$ and OS (HR 0.57 $\mathrm{p}<0.0001)$ in the context of modern medical oncology treatment, adding to a growing body of literature supporting routine colorectal primary resection even when the metastases are not resectable(17). However, timing this resection is difficult; although the colorectal lesion may become symptomatic during chemotherapy, the possibility of complications from resection of the primary disease delaying systemic therapy is more concerning $(18,19)$. Peri-operative mortality is $2.7 \%$ and major morbidity is $11.8 \%(5)$ when the primary is resected in this context(20) but the alternatives also have significant risks: colonic stenting has a $1.2 \%$ immediate and $3.1-5.1 \%$ cumulative perforation rate $(21,22)$ even in the hands of experienced proceduralists(23). No clear pathway for management of the primary tumour has been established. 
Primary tumour location influenced both PFS and OS in this cohort in keeping with evidence suggesting that outcomes are inferior for metastatic right colonic lesions $(24,25)$. The clinically silent nature of right sided disease, different tumour biology and potentially different patterns of venous drainage contribute to a poorer overall outcome $(25,26)$.

PFS was poorer for those who had synchronous resection of primary and distant disease rather than staged, but this did not affect OS. Prior literature suggests that neither PFS nor OS should be affected by the timing of resections(27) and that the principal impact is on the use of hospital resources(28). Quality of resection was critical; R0 and R1 resection of metastatic disease resulted in significant improvement in overall survival while R2 resection was little different from no resection.

This analysis represents an update on the Australian management of Stage 4 disease from 2009 to 2015. Level one evidence for the management of stage 4 colorectal adenocarcinoma is lacking due to the difficulty of enrolling patients in available trials: the SUPER trial(29) closed early and no results have been reported from ISAAC(30), SYNCHRONOUS(31) or CAIRO4(32).

There are a number of limitations. Although we account for the number of metastatic sites, we have not aressed. strictly assessed the volume of liver disease which has previously been an independent predictor of overall survival(33). Nor do we have a measure of surgical complications for those undergoing resection. Quality of life measures are not assessed in this series.

\section{CONCLUSION:}

It is critical that there is appropriate selection of curative intent strategies for patients with synchronous metastatic colorectal cancer because a proportion of patients can be cured with intensive chemotherapy and surgical resection of primary and metastatic disease. There are a significant number of disease and patient variables that must be considered as the appropriate management strategy is formulated, ideally with multidisciplinary input. High quality prospective data remain elusive and we continue to be guided by the patient's response to treatment as chief determinant of our management strategy. 
Palliation still typically involves colorectal primary resection. Aggressive adjuvant or definitive medical oncology treatment significantly delays progression and improves survival and should be considered for all fit patients irrespective of disease parameters.

\section{Acknowledgement:}

The authors thank Michael Harold for his ongoing assistance with the maintenance of this registry, the provision and verification of this dataset.

\section{Conflicts of interest}

None.

\section{References:}

1. NCCN. Clinical Practice Guidelines in Oncology (NCCN Guidelines ${ }^{\circledR}$ Colon Cancer). National comprehensive cancer network; 2016.

2. Buchs NC, Ris F, Majno PE, Andres A, Cacheux W, Gervaz P, et al. Rectal outcomes after a liver-first treatment of patients with stage IV rectal cancer. Ann Surg Oncol. 2015;22(3):931-7.

3. de Rosa A, Gomez D, Hossaini S, Duke K, Fenwick SW, Brooks A, et al. Stage IV colorectal cancer: outcomes following the liver-first approach. J Surg Oncol. 2013;108(7):444-9.

4. Lam VWT, Laurence JM, Pang T, Johnston E, Hollands MJ, Pleass HCC, et al. A systematic review of a liver-first approach in patients with colorectal cancer and synchronous colorectal liver metastases. Hpb. 2014;16(2):101-8.

5. Scheer MG, Sloots CE, van der Wilt GJ, Ruers TJ. Management of patients with asymptomatic colorectal cancer and synchronous irresectable metastases. Annals of oncology/ESMO. 2008;19(11):1829-35.

6. Stillwell AP, Buettner PG, Ho YH. Meta-analysis of survival of patients with stage IV colorectal cancer managed with surgical resection versus chemotherapy alone. World J Surg. 2010;34(4):797807.

7. Yun JA, Huh JW, Park YA, Cho YB, Yun SH, Kim HC, et al. The role of palliative resection for asymptomatic primary tumor in patients with unresectable stage IV colorectal cancer. Dis Colon Rectum. 2014;57(9):1049-58.

8. Tsukamoto S, Kinugasa Y, Yamaguchi T, Shiomi A. Survival after resection of liver and lung colorectal metastases in the era of modern multidisciplinary therapy. Int J Colorectal Dis. 2014;29(1):81-7.

9. Shao YC, Chang YY, Lin JK, Lin CC, Wang HS, Yang SH, et al. Neoadjuvant chemotherapy can improve outcome of colorectal cancer patients with unresectable metastasis. Int J Colorectal Dis. 2013;28(10):1359-65. 
10. Ghiringhelli F, Hennequin A, Drouillard A, Lepage C, Faivre J, Bouvier AM. Epidemiology and prognosis of synchronous and metachronous colon cancer metastases: a French population-based study. Dig Liver Dis. 2014;46(9):854-8.

11. Nordlinger B, Sorbye H, Glimelius B, Poston GJ, Schlag PM, Rougier P, et al. Perioperative FOLFOX4 chemotherapy and surgery versus surgery alone for resectable liver metastases from colorectal cancer (EORTC 40983): long-term results of a randomised, controlled, phase 3 trial. Lancet Oncology. 2013;14(12):1208-15.

12. Doat S, Thiebaut A, Samson S, Ricordeau P, Guillemot D, Mitry E. Elderly patients with colorectal cancer: treatment modalities and survival in France. National data from the ThInDiT cohort study. Eur J Cancer. 2014;50(7):1276-83.

13. Crosara Teixeira M, Marques DF, Ferrari AC, Alves MF, Alex AK, Sabbaga J, et al. The effects of palliative chemotherapy in metastatic colorectal cancer patients with an ECOG performance status of 3 and 4. Clin Colorectal Cancer. 2015;14(1):52-7.

14. Kotake K, Asano M, Ozawa H, Kobayashi H, Sugihara K. Tumour characteristics, treatment patterns and survival of patients aged 80 years or older with colorectal cancer. Colorectal Dis. 2015;17(3):205-15.

15. Field K, Wong HL, Shapiro J, Kosmider S, Tie J, Bae S, et al. Developing a national database for metastatic colorectal cancer management: perspectives and challenges. Intern Med J. 2013;43(11):1224-31.

16. Seymour MT, Thompson LC, Wasan HS, Middleton G, Brewster AE, Shepherd SF, et al. Chemotherapy options in elderly and frail patients with metastatic colorectal cancer (MRC FOCUS2): an open-label, randomised factorial trial. Lancet. 2011;377(9779):1749-59.

17. Faron M, Pignon JP, Malka D, Bourredjem A, Douillard JY, Adenis A, et al. Is primary tumour resection associated with survival improvement in patients with colorectal cancer and unresectable synchronous metastases? A pooled analysis of individual data from four randomised trials. Eur J Cancer. 2015;51(2):166-76.

18. Seo GJ, Park JW, Yoo SB, Kim SY, Choi HS, Chang HJ, et al. Intestinal complications after palliative treatment for asymptomatic patients with unresectable stage IV colorectal cancer. J Surg Onc. 2010;102(1):94-9.

19. Kleespies A, Fuessl KE, Seeliger H, Eichhorn ME, Muller MH, Rentsch M, et al. Determinants of morbidity and survival after elective non-curative resection of stage IV colon and rectal cancer. Int J Colorectal Dis. 2009;24(9):1097-109.

20. Cirocchi R, Trastulli S, Abraha I, Vettoretto N, Boselli C, Montedori A, et al. Non-resection versus resection for an asymptomatic primary tumour in patients with unresectable Stage IV colorectal cancer (Review). Cochrane collaboration. 2012(8):1-35.

21. Meisner S, Gonzalez-Huix F, Vandervoort JG, Repici A, Xinopoulos D, Grund KE, et al. SelfExpanding Metal Stenting for Palliation of Patients with Malignant Colonic Obstruction: Effectiveness and Efficacy on 255 Patients with 12-Month's Follow-up. Gastroenterol Res Pract.

2012;2012:296347.

22. Gianotti L, Tamini N, Nespoli L, Rota M, Bolzonaro E, Frego R, et al. A prospective evaluation of short-term and long-term results from colonic stenting for palliation or as a bridge to elective operation versus immediate surgery for large-bowel obstruction. Surgical endoscopy. 2013;27(3):832-42.

23. van Hooft JE, Bemelman WA, Oldenburg B, Marinelli AW, Holzik MFL, Grubben MJ, et al. Colonic stenting versus emergency surgery for acute left-sided malignant colonic obstruction: a multicentre randomised trial. Lancet Oncology. 2011;12(4):344-52. 
24. Modest DP, Schulz C, von Weikersthal LF, Quietzsch D, von Einem JC, Schalhorn A, et al. Outcome of patients with metastatic colorectal cancer depends on the primary tumor site (midgut vs. hindgut): analysis of the FIRE1-trial (FuFIRI or mIROX as first-line treatment). Anti-cancer drugs. 2014;25(2):212-8.

25. N. Chafai, C. L. H. Chan, E. L. Bokey, O. F. Dent, G. Sinclair, Chapuis PH. What factors influence survival in patients with unresected synchronous liver metastases after resection of colorectal cancer? Colorectal Disease. 2004;7:176-81.

26. Brule SY, Jonker DJ, Karapetis CS, O'Callaghan CJ, Moore MJ, Wong R, et al. Location of colon cancer (right-sided versus left-sided) as a prognostic factor and a predictor of benefit from cetuximab in NCIC CO.17. Eur J Cancer. 2015;51(11):1405-14.

27. JM B, B F, M R, E C, E B, K. B. Disease-Free Survival after Simultaneous or Delayed Resection of Synchronous Colorectal Liver Metastasis and Primary Cancer. Hepato-Gastroenterology 2014 61(132):1074-81.

28. Javed MA, Sheel AR, Sheikh AA, Page RD, Rooney PS. Size of metastatic deposits affects prognosis in patients undergoing pulmonary metastectomy for colorectal cancer. Ann R Coll of Surg Eng. 2014;96(1):32-6.

29. Platell C. The SUPER Study: A randomised phase III multicentre trial evaluating the role of palliative surgical resection of the primary tumour in patients with metastatic colorectal cancer. ANZCTR. 2010.

30. A O. ISAAC: a randomised trial for patients with asymptomatic advanced colorectal cancer to look at the benefits of undergoing surgical removal of their primary tumour before receiving chemotherapy for metastatic disease. ISRCTN. 2015.

31. N R. Resection of the primary tumour versus no resection prior to systemic therapy in patients with colon cancer and synchronous unresectable metastases (UICC stage IV): SYNCHRONOUS a randomised controlled multicentre trial. 2016.

32. 't Lam-Boer J1, Mol L, Verhoef C, de Haan AF, Yilmaz M, Punt CJ, et al. The CAIRO4 study: the role of surgery of the primary tumour with few or absent symptoms in patients with synchronous unresectable metastases of colorectal cancer--a randomized phase III study of the Dutch Colorectal Cancer Group (DCCG). BMC Cancer. 2014;14:741.

33. Yoon YS, Kim CW, Lim SB, Yu CS, Kim SY, Kim TW, et al. Palliative surgery in patients with unresectable colorectal liver metastases: a propensity score matching analysis. J surg onc.

2014;109(3):239-44.

\section{List of supporting information:}

Document S1 "Management of Synchronous metastatic rectal adenocarcinoma"

Figure S1 "Reasons for resection of the colorectal primary in the palliative intent group"

Figure S2 "The effect of treatment intent and resection of colorectal primary on progression free and overall survival" 


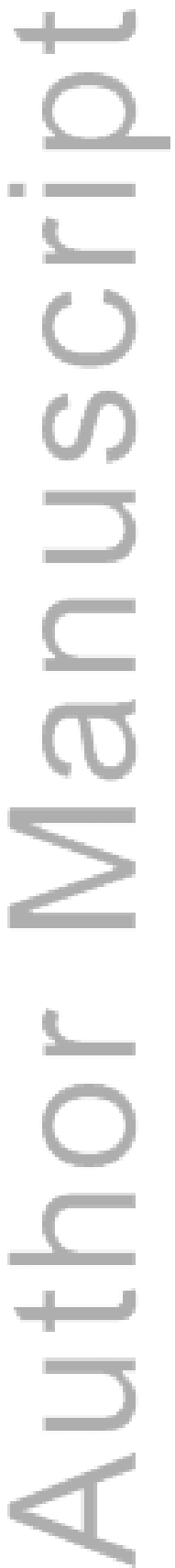

This article is protected by copyright. All rights reserved. 


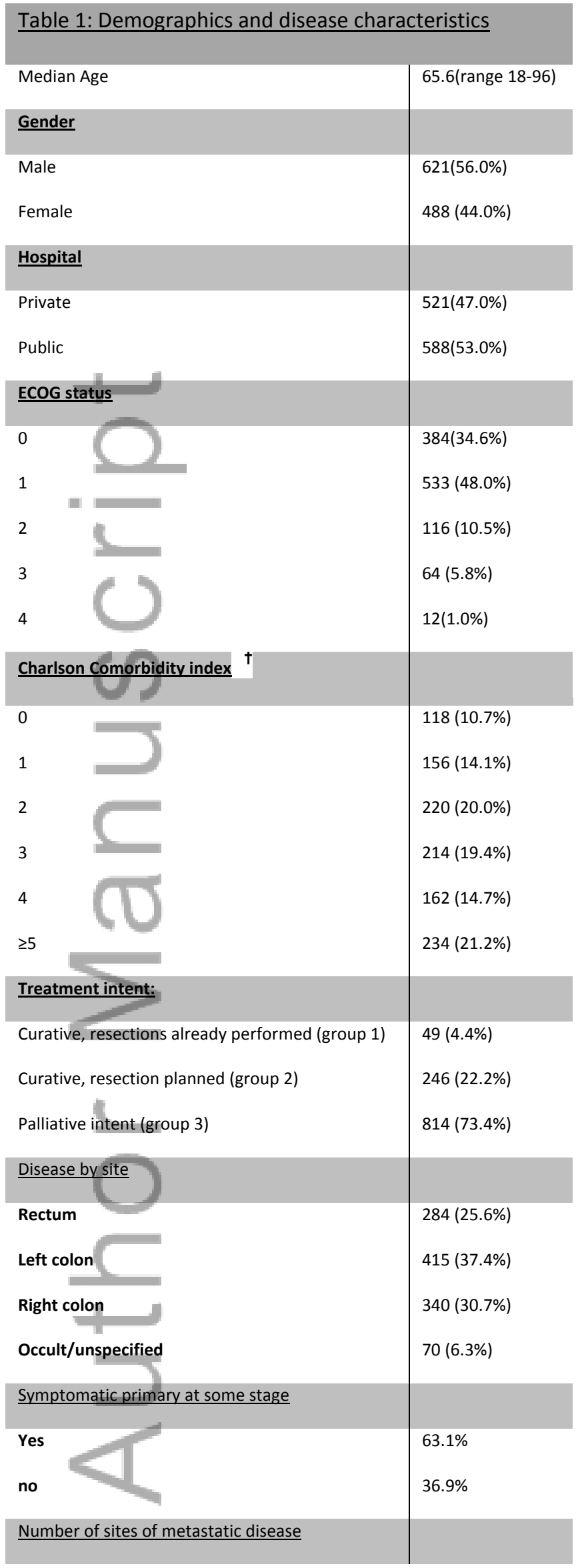

This article is protected by copyright. All rights reserved. 


\begin{tabular}{l|l}
1 & $585(52.6 \%)$ \\
$\mathbf{3}$ & $326(29.4 \%)$ \\
4 or more & $146(13.2 \%)$ \\
\hline
\end{tabular}

excludes scores pertaining to the metastatic cancer itself
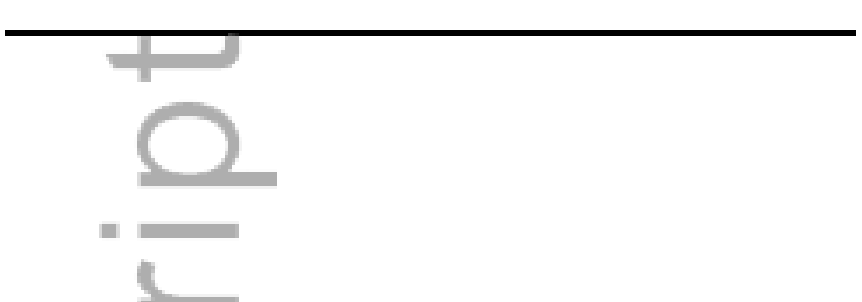

(1)

N

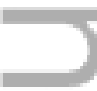

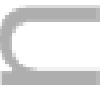
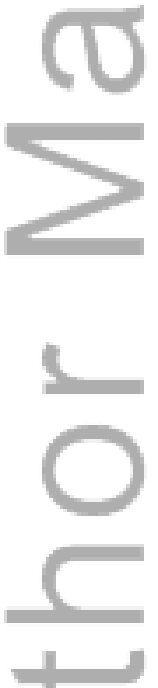

$+2$

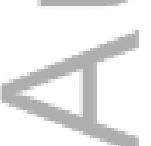

This article is protected by copyright. All rights reserved. 


\begin{tabular}{|c|c|c|c|c|c|c|c|c|}
\hline \multirow[b]{3}{*}{ Variable } & \multicolumn{4}{|c|}{ Progression free survival } & \multicolumn{4}{|c|}{ Overall survival } \\
\hline & \multicolumn{2}{|c|}{ Univariate } & \multicolumn{2}{|c|}{ Multivariate } & \multicolumn{2}{|c|}{ Univariate } & \multicolumn{2}{|c|}{ Multivariate } \\
\hline & $\mathrm{HR}$ & $P$ & HR & $P$ & $\mathrm{HR}$ & $P$ & $\underline{\mathrm{HR}}$ & $P$ \\
\hline Age & 1.01 & $<0.0001$ & & & 1.03 & $<0.0001$ & 1.01 & 0.005 \\
\hline Male sex $v$ female & 1.02 & 0.83 & & & 1.02 & 0.9 & & \\
\hline Private hospital v public & 0.931 & 0.3 & & & 0.84 & 0.03 & & \\
\hline Modified Charlson score & 1.05 & $<0.001$ & 0.961 & 0.03 & 1.1 & $<0.0001$ & & \\
\hline Number of metastatic sites & 1.22 & $<0.0001$ & 1.1 & 0.004 & 1.3 & $<0.0001$ & 1.1 & 0.006 \\
\hline Log (Duration of first-line chemotherapy) & 0.914 & $<0.0001$ & & & 0.83 & $<0.0001$ & 0.96 & 0.002 \\
\hline Biological agent (Bevacizumab) used & 0.849 & 0.02 & 0.77 & 0.0002 & 0.75 & 0.0002 & 0.71 & 0.0003 \\
\hline Primary resection performed & 0.47 & $<0.0001$ & 0.58 & $<0.0001$ & 0.41 & $<0.0001$ & 0.57 & $<0.0001$ \\
\hline \multicolumn{9}{|l|}{$\underline{\text { Primary site }}$} \\
\hline Left colon (reference group) & 1 & & 1 & & 1 & & 1 & \\
\hline Right colc & 1.18 & 0.05 & 1.2 & 0.02 & 1.3 & 0.006 & 1.3 & 0.02 \\
\hline Occult/unspecified primary & 1.28 & 0.08 & 0.89 & 0.4 & 1.9 & $<0.0001$ & 1.3 & 0.1 \\
\hline Rectum & 0.98 & 0.8 & 0.83 & 0.04 & 0.98 & 0.8 & 0.81 & 0.05 \\
\hline \multicolumn{9}{|l|}{ ECOG status } \\
\hline ECOG 0 (reference group) & 1 & & 1 & & 1 & & 1 & \\
\hline ECOG 1 & 1.4 & $<0.0001$ & 1.2 & 0.02 & 1.7 & $<0.0001$ & 1.3 & 0.004 \\
\hline ECOG 2 & 2.6 & $<0.0001$ & 1.7 & $<0.0001$ & 4.5 & $<0.0001$ & 2.3 & $<0.0001$ \\
\hline ECOG 3 & 4.3 & $<0.0001$ & 3.1 & $<0.0001$ & 9.3 & $<0.0001$ & 5 & $<0.0001$ \\
\hline ECOG 4 & 91.8 & $<0.0001$ & 76.3 & $<0.0001$ & 179 & $<0.0001$ & 84.0 & $<0.0001$ \\
\hline \multicolumn{9}{|l|}{ Nature of metastasis resection } \\
\hline R0 (reference group) & 1 & & 1 & & 1 & & 1 & \\
\hline R1 & 1.8 & 0.04 & 1.6 & 0.1 & 1.5 & 0.4 & 1.2 & 0.7 \\
\hline R2 & 2.8 & $<0.0001$ & 1.9 & 0.002 & 4 & $<0.0001$ & 2.2 & 0.004 \\
\hline
\end{tabular}




\begin{tabular}{|c|c|c|c|c|c|c|c|c|}
\hline no resection & 3.2 & $<0.0001$ & 2 & $<0.001$ & 6.5 & $<0.0001$ & 2.7 & $<0.0001$ \\
\hline \multicolumn{9}{|l|}{$\underline{\text { Treatment intent }}$} \\
\hline group 1 (reference group) & 1 & & 1 & & 1 & & 1 & \\
\hline group 2 & 2 & 0.002 & 1.6 & 0.04 & 3.7 & 0.002 & 2.8 & 0.02 \\
\hline group 3 & 4.2 & $<0.0001$ & 1.9 & 0.01 & 13.4 & $<0.0001$ & 4.2 & 0.002 \\
\hline
\end{tabular}

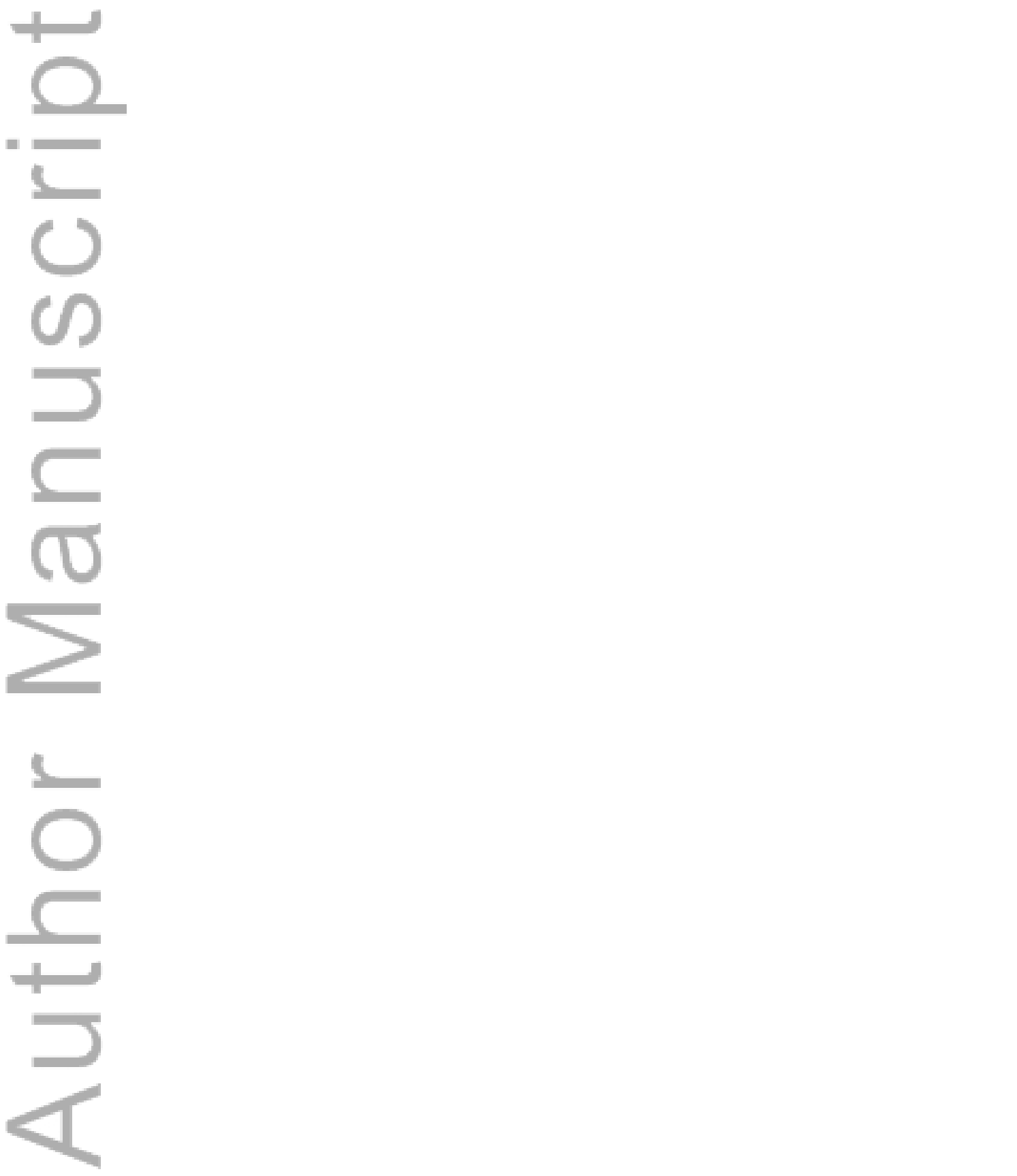

This article is protected by copyright. All rights reserved. 

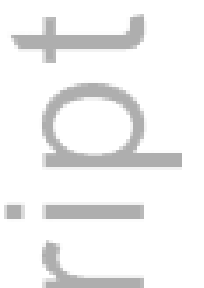

Figure 1: Premature Cessation of First-line chemotherapy and utilisation of second-line treatment

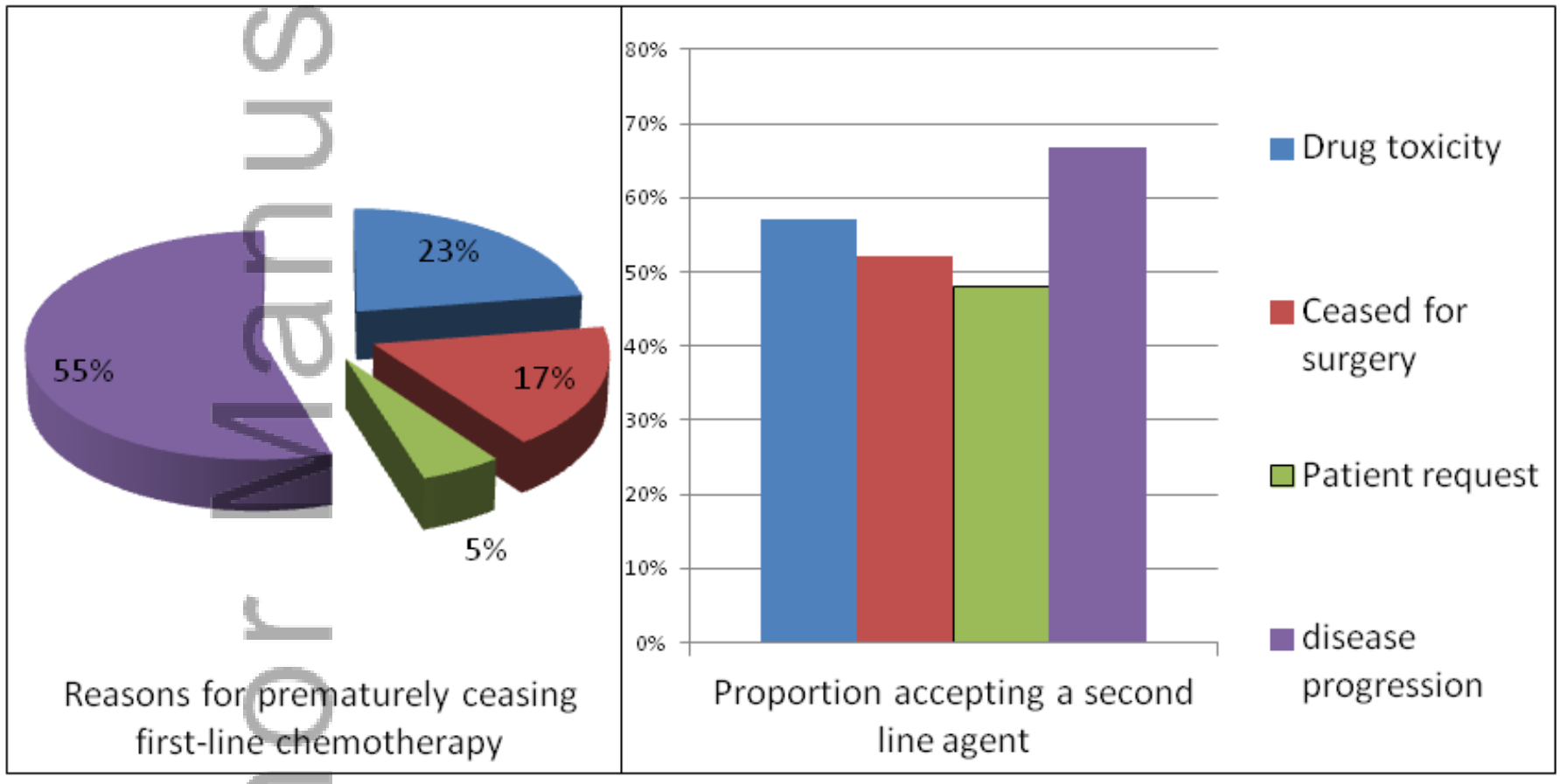

figure 1.tif

This article is protected by copyright. All rights reserved. 


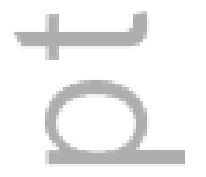

Figure 2: Surgical treatment pathway by Treatment intent group.

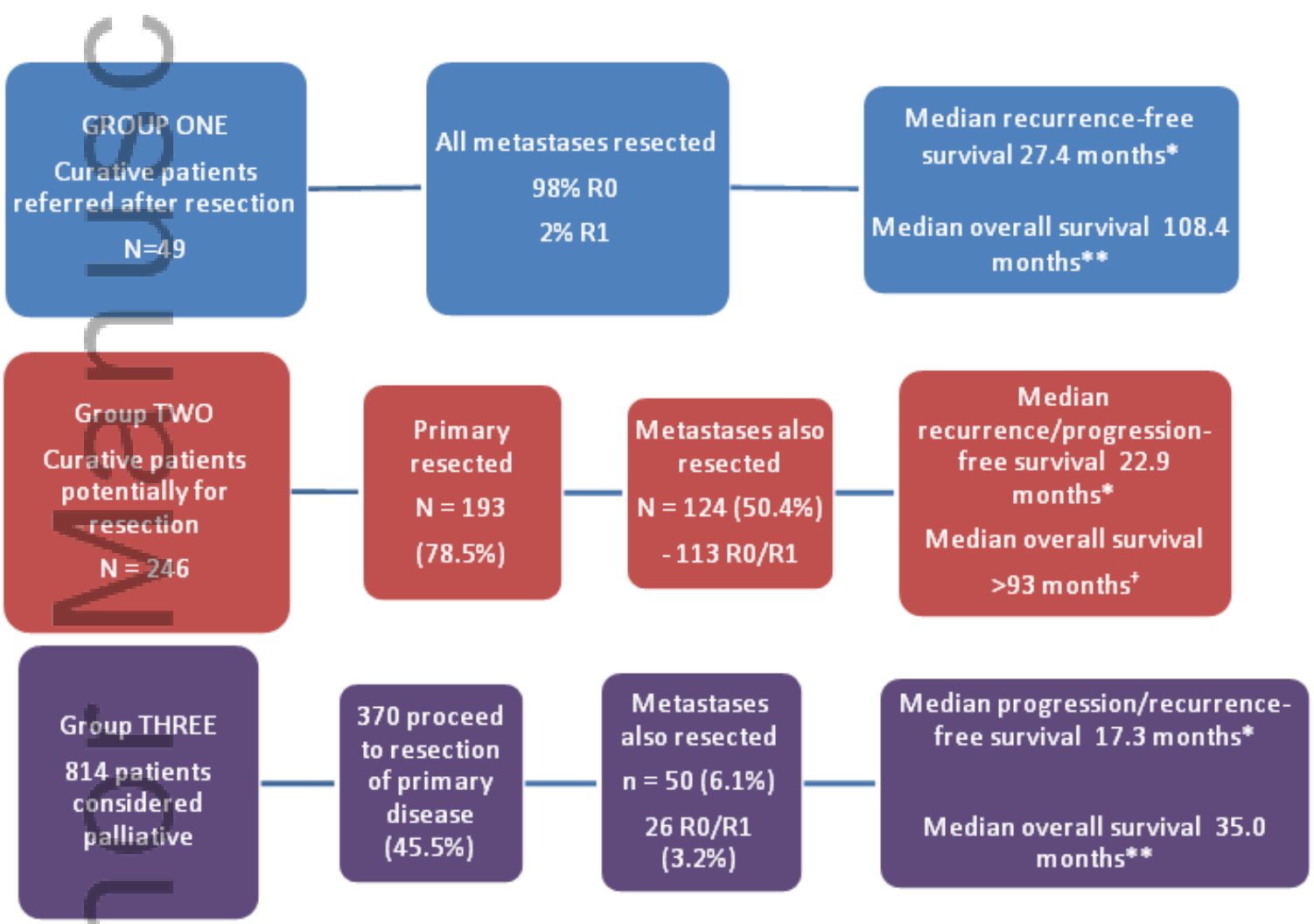

${ }^{*} \mathrm{P} 0.2$ for PFS across the treatment intent groups ${ }^{* *} \mathrm{P} 0.0002$ for OS across treatment intent groups

${ }^{+}>60 \%$ survival at analysis at 93 months

figure 2.tif

This article is protected by copyright. All rights reserved. 


\section{University Library}

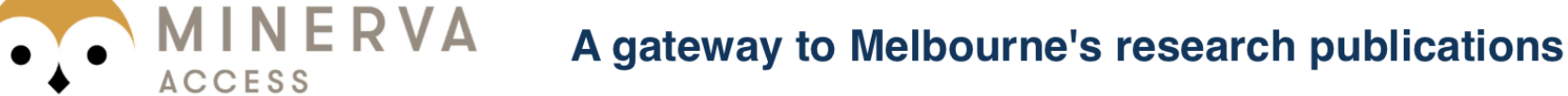

Minerva Access is the Institutional Repository of The University of Melbourne

Author/s:

Malouf, P;Gibbs, P;Shapiro, J;Sockler, J;Bell, S

Title:

Australian contemporary management of synchronous metastatic colorectal cancer

Date:

2018-01-01

Citation:

Malouf, P., Gibbs, P., Shapiro, J., Sockler, J. \& Bell, S. (2018). Australian contemporary

management of synchronous metastatic colorectal cancer. ANZ JOURNAL OF SURGERY, 88 (1-2), pp.71-76. https://doi.org/10.1111/ans.13619.

Persistent Link:

http://hdl.handle.net/11343/291224 